CIFRAS DE HOY Rev Chil Salud Pública 2014; Vol 18 (3): 292-293

\section{SALUD PÚBLICA COMO INVESTIGACIÓN UNIVERSITARIA DE POSGRADO}

El debate en The Lancet ${ }^{1}$ nos animó a preguntarnos qué hay en las bases de datos de tesis de posgrado de las escuelas de historia de las universidades chilenas accesibles online, relacionadas con salud.

Usamos como palabras clave salud, medicina, hospital e historia.

Entramos al repositorio Portal de Tesis Electrónicas (http://www.tesis. uchile.cl, agosto del 2014) de la Universidad de Chile, eligiendo posgrados y Facultad de Filosofía y Humanidades. Encontramos 305 tesis publicadas con la palabra clave historia, de las cuales solo tres tenían la palabra clave salud, todas ellas correspondientes al grado de magíster, dos con mención historia de Chile y una con mención etnohistoria. Dos de ellas del 2007 y una del 2010. Otras cuatro estaban vinculadas a la palabra clave medicina, todas ellas de magíster. Dos de historia (mención historia de Chile), una mención en literatura y otra sin clasificar. Tres tesis contenían la palabra salud, pero no historia; dos magísteres en género, y una sin posibilidades de identificar su origen (Tabla 1).

No encontramos ninguna tesis doctoral en historia y salud o medicina. En Facultades de Medicina y de Odontología, no encontramos tesis con la palabra clave historia.

De otras 10 universidades en que realizamos una búsqueda dirigida, solo dos tenían plataformas operativas. El buscador de USACH solo devolvió tesis de pregrado. Entre 20 resultados de historia y salud, 13 eran de ingeniería informática, y solo uno de los otros siete era de la Facultad de Humanidades (tesis para título de profesor de estado en historia y geografía). La Universidad de Talca tiene un buen portal de tesis electrónicas, sin carrera de historia ni posgrado. La búsqueda (salud e historia) resultó en 15 tesis de pregrado y un magíster en gerencia.

Más allá de las lamentaciones por el escaso desarrollo de los sitios institucionales como repositorios que publiquen el trabajo de investigación de los estudiantes, destacamos la reducida investigación histórica en el área. Para los datos disponibles, la balanza parece inclinarse hacia el alegato de Horton. 
Tabla 1. Resultados de búsqueda con las siguientes restricciones: "Facultad de Filosofía y Humanidades”, “Tesis de Posgrado”. Palabras clave fueron buscadas usando los campos 'materia' y 'contiene'.

\begin{tabular}{lcc}
\hline Título de tesis & $\begin{array}{c}\text { Año } \\
\text { publicado }\end{array}$ & Departamento
\end{tabular} Título de grado

Palabras clave: historia, salud

Una mirada historiográfica acerca del desarrollo de la institucionalidad sanitaria chilena: 1889-1989

“Deber entrar a medicinarse...": La casa, el adentro y la purificación. El Hospital San Francisco de Borja entre 1830 y 1870

En medio de la gestación de la medicina intercultural: machis y sistema público de salud

Palabras clave: historia, medicina, NO salud

Argumentos filosóficos para una re-definición de la medicina moderna

La ciudad médica-industrial: melancólico, delirante y furioso; el psiquiátrico de Santiago de Chile 1852-1930

La fragilidad de la simbiosis médico judicial y la producción de una antropología criminal. Juzgados del crimen de Santiago, 1874-1906

José Celestino Mutis y la medicina social en el Nuevo Reino de Granada (siglo XVIII): estudio y antología

Palabras clave: salud, no historia

El significado de la salud y la enfermedad en el pueblo de Talabre: un acercamiento desde la perspectiva de Género

Estudio de caso sobre la incorporación de perspectiva de Género en un centro de salud mental comunitaria

Estudio de caso acerca de la incorporación de perspectiva de género en el tratamiento para personas con problemas derivados del consumo de alcohol u otras drogas en

un centro de salud mental comunitaria
2007

Departamento de Ciencias Históricas

Magíster en Historia Mención en Historia de Chile

Departamento de Ciencias

Magíster en Historia Históricas Mención en Historia de Chile

2010

Departamento de Ciencias

Magíster en Historia Históricas

\section{Departamento de} Filosofía

Departamento de Ciencias Históricas

Departamento de Historia

Departamento de Literatura

2011
Magíster en Filosofía

Mención en Axiología

Magíster en Historia Mención en Historia de Chile

Magíster en Historia Mención en Historia de Chile

Magíster en Literatura
Centro de Estudios de

Género y Cultura en

América Latina

Centro de Estudios de Género

Magíster en Género

Magíster en Estudios de Género

(archivo no cargó)

(archivo no cargó) 